\title{
Sodium Ferric Gluconate Complex in Sucrose
}

National Cancer Institute

\section{Source}

National Cancer Institute. Sodium Ferric Gluconate Complex in Sucrose. NCI Thesaurus.

Code C78185.

A compound containing elemental iron as the sodium salt of a ferric ion carbohydrate complex in an alkaline aqueous solution with approximately $20 \%$ sucrose $\mathrm{w} / \mathrm{v}$ in water for injection, used to replete the total body content of iron. Iron is critical for normal hemoglobin and myog lobin syntheses to maintain oxygen transport and various enzymatic processes, including the biosynthesis of deoxyribonucleotides catalyzed by ribonucleotide reductase (RNR). 